\title{
Saccharomyces arboricolus sp. nov., a yeast species from tree bark
}

Correspondence

Feng-Yan Bai

baify@im.ac.cn

\author{
Shi-An Wang ${ }^{1,2}$ and Feng-Yan Bai ${ }^{1}$
}

${ }^{1}$ Systematic Mycology and Lichenology Laboratory, Institute of Microbiology, Chinese Academy of Sciences, Beijing 100101, PR China

${ }^{2}$ Graduate School of the Chinese Academy of Sciences, Beijing 100039, PR China
Seven species are currently included in the genus Saccharomyces Meyen ex Reess as redefined recently by Kurtzman (2003), based on multigene sequence analysis (Kurtzman \& Robnett, 2003). During the investigation of the diversity of ascomycetous yeasts associated with plant materials from China, three strains, $H-6^{T}, Z X-15$ and ZX20 , isolated from the bark of broadleaf trees, were found to represent a novel species of the genus Saccharomyces by physiological characterization, rRNA gene sequencing and electrophoretic karyotyping.

Yeast strains living in bark were isolated by using the enrichment method. Pieces of bark with or without exudates from independent trees were cut with a sterile scalpel and placed into sterile plastic tubes containing $3 \mathrm{ml}$ liquid enrichment medium. The medium was made according to Sniegowski et al. (2002) with minor modifications, containing $(\mathrm{w} / \mathrm{v}) 0.3 \%$ yeast extract, $0.3 \%$ malt extract, $0.5 \%$ peptone, $0.5 \%$ sucrose, $0.5 \%$ galactose, $7.6 \%(\mathrm{v} / \mathrm{v})$ ethanol, $200 \mu \mathrm{g}$ chloramphenicol $\mathrm{ml}^{-1}$ and $1 \mathrm{ml} 1 \mathrm{M} \mathrm{HCl}$ per litre. The cultures were incubated at room temperature without shaking for 7 to 14 days. Aliquots $(100 \mu \mathrm{l})$ of the $10^{-2}$ to $10^{-4}$ diluted enrichment culture was spread on plate medium made by adding $2 \%$ agar to the liquid enrichment medium. After 2 days incubation at room temperature or $25{ }^{\circ} \mathrm{C}$, colonies with

Abbreviation: ITS, internal transcribed spacer.

The GenBank/EMBL/DDBJ accession numbers for the ITS region and 26S rRNA gene D1/D2 domain sequences of strain $\mathrm{H}-6^{\top}$ are EF580917 and EF580918, respectively.

A supplementary table showing nucleotide mismatches in the D1/D2 domain and ITS region sequences between the type strains of Saccharomyces species is available with the online version of this paper. different morphological characters were transferred into malt extract agar slants for further purification and examination.

Strain $\mathrm{H}-6^{\mathrm{T}}$ was isolated from the bark of Quercus fabri Hance collected in the Qinling Mountains, Shaanxi Province in western China. Strains ZX-15 and ZX-20 were isolated from the bark of Castanopsis orthacantha Franch collected from Yunnan Province in south-west China. Morphological, physiological and biochemical characteristics were examined according to standard methods commonly used in yeast taxonomy (Yarrow, 1998). Assimilation of nitrogen compounds was investigated on solid media with starved inocula (Nakase \& Suzuki, 1986).

Nuclear DNA was extracted by the method of Makimura et al. (1994). The DNA fragment covering the ITS region (including 5.8S rDNA) and the large-subunit rDNA D1/D2 domain was amplified and sequenced as described previously (Lu et al., 2004). Molecular phylogenetic analysis was performed by the methods described by Bai et al. (2002). Reference sequences were retrieved from GenBank under the accession numbers indicated in the trees.

Intact yeast chromosomal DNA was prepared by the method of Bai et al. (2000). Chromosomal DNA bands were separated in $1 \%(\mathrm{w} / \mathrm{v})$ agarose gel in $0.5 \times \mathrm{TBE}$ buffer (45 mM Tris/borate, $1 \mathrm{mM}$ EDTA, $\mathrm{pH} 8.0$ ) in a contourclamped homogeneous electric field electrophoresis apparatus (CHEF-Mapper XA; Bio-Rad). Electrophoresis was carried out at $6 \mathrm{~V} \mathrm{~cm}^{-1}$ for $16 \mathrm{~h}$ with a switch time of $60 \mathrm{~s}$ and then for $11 \mathrm{~h}$ with a switch time of $90 \mathrm{~s}$. The temperature of the running buffer was maintained at 12$14{ }^{\circ} \mathrm{C}$. After electrophoresis, the gel was stained in ethidium bromide solution $\left(0.5 \mu \mathrm{g} \mathrm{ml}^{-1}\right)$ for $30 \mathrm{~min}$, 
destained in distilled water and viewed under UV light (302 nm) with the AlphaImager 2200 gel documentation system (Alpha Innotech). Saccharomyces cerevisiae (YNN 295) chromosomal DNA (Bio-Rad) was used as the molecular size marker.

\section{Sequence analyses}

Strains $\mathrm{H}-6^{\mathrm{T}}$, ZX-15 and ZX-20 have identical sequences in both the D1/D2 domain and ITS region, indicating their conspecificity. They were clustered in the S. cerevisiae clade (Kurtzman \& Robnett, 2003) with $100 \%$ bootstrap support in the tree constructed from the concatenated sequences of the ITS region and the D1/D2 domain (Fig. 1). However, their phylogenetic position among accepted Saccharomyces species was not resolved. Satisfactory resolution of the phylogenetic relationships among Saccharomyces species is problematic. The combined 18S-5.8S-26S rDNA sequence analysis did not resolve the species relationships of the genus (Kurtzman \& Robnett, 2003). The phylogeny of Saccharomyces species determined from a dataset consisting of nucleotide sequences from 18S, 5.8S/alignable ITS and $26 \mathrm{~S}$ (three regions) rDNAs, EF- $1 \alpha$, as well as mitochondrial small-subunit rDNA and COX II (Kurtzman \& Robnett, 2003) was not congruent with that determined from a concatenated dataset composed of 106 genes (Rokas et al., 2003). Nevertheless, the inclusion of the species represented by these three strains in the genus Saccharomyces is clear because, even in the tree drawn from either the D1/D2 or the ITS data, they were located in the S. cerevisiae clade of the 'Saccharomyces complex' with $100 \%$ bootstrap support (data not shown).

The result of a BLAST search in GenBank with the D1/D2 sequence of strain $\mathrm{H}-6^{\mathrm{T}}$ as the query showed that the closest match was the sequence of Saccharomyces kudriavzevii NRRL Y-27340 (Kurtzman \& Robnett, 2003) (incorrectly named Saccharomyces kunashirensis in the GenBank record). The sequences differed by 3 substitutions. In the ITS region, strain $\mathrm{H}-6^{\mathrm{T}}$ differed from strain NRRL Y-27340 by 18 substitutions and two indels. In the phylogenetic tree based on the combined sequences of the rDNA ITS region and large subunit D1/D2 domain, strain NRRL Y-27340 formed a subclade with the type strain of S. kudriavzevii, IFO $1802^{\mathrm{T}}$, and was clearly separated from strain $\mathrm{H}-6^{\mathrm{T}}$ (Fig. 1).

Large subunit D1/D2 domain sequence comparison between strain $\mathrm{H}-6^{\mathrm{T}}$ and the type strains of accepted Saccharomyces species showed that strain $\mathrm{H}-6^{\mathrm{T}}$ was most similar to Saccharomyces paradoxus, Saccharomyces cariocanus and S. kudriavzevii; it differed from the three described species by four, five and six substitutions, respectively. However, in the ITS region, strain $\mathrm{H}-6^{\mathrm{T}}$ differed from these three species more significantly (19-20 substitutions) than from the other species of the genus (14-18 substitutions) (see Supplementary Table S1).

\section{Electrophoretic karyotyping}

The electrophoretic karyotypes of strains $\mathrm{H}-6^{\mathrm{T}}, \mathrm{ZX}-15$ and ZX-20 were compared with those of the type strains of the species currently accepted in the genus Saccharomyces (Fig. 2). The three strains showed similar chromosomal banding patterns which differed clearly from those of the other species compared, especially in the molecular sizes of the largest chromosomes. Twelve to thirteen chromosome bands were resolved for the three strains, with molecular sizes ranging approximately from 250 to $2000 \mathrm{~kb}$. The molecular sizes of the largest bands of the other species compared were usually about $2200 \mathrm{~kb}$. Strains ZX-15 and ZX-20 have almost identical patterns, which differed slightly from that of strain $\mathrm{H}-6^{\mathrm{T}}$. This is in agreement with their sources. As wider bands or bands with stronger relative intensity may correspond to doublets or triplets, it is reasonable to infer that each of the three strains contains at least 16 chromosomes (Fig. 2).

Previous studies have shown that the species of Saccharomyces sensu stricto exhibit relatively homogeneous karyotypes compared with those of species of

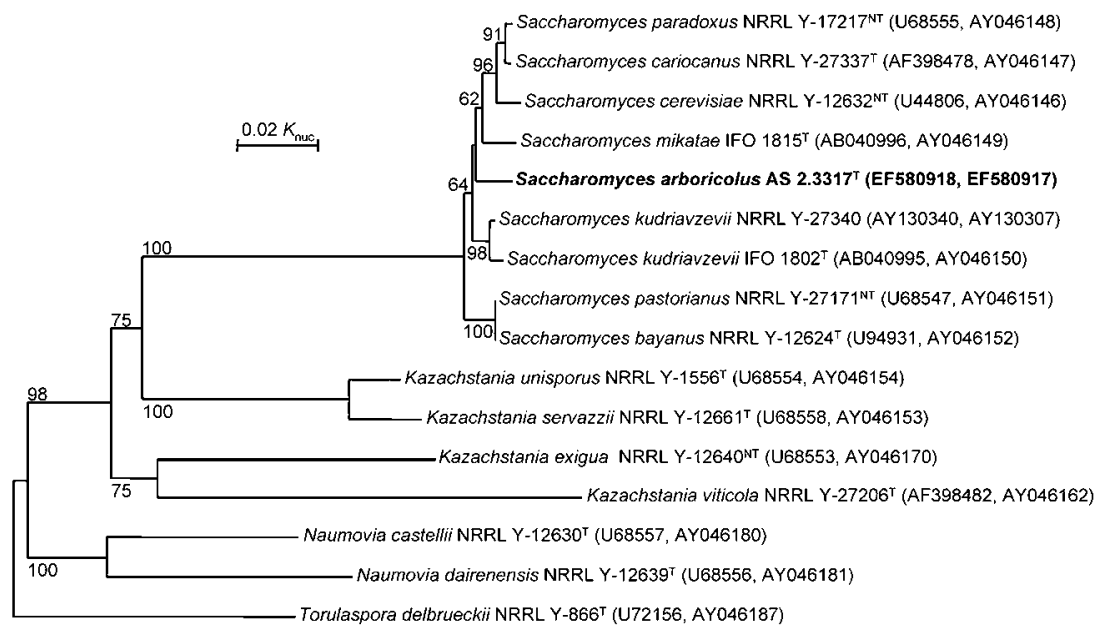

Fig. 1. Phylogenetic tree drawn from neighbour-joining analysis of the combined sequences of the ITS (including 5.8S rDNA) region and 26S rDNA D1/D2 domain, depicting the relationships of Saccharomyces arboricolus sp. nov. with closely related taxa. Bootstrap percentages over $50 \%$ from 1000 bootstrap replicates are shown. Reference sequences were retrieved from GenBank under the accession numbers indicated. 


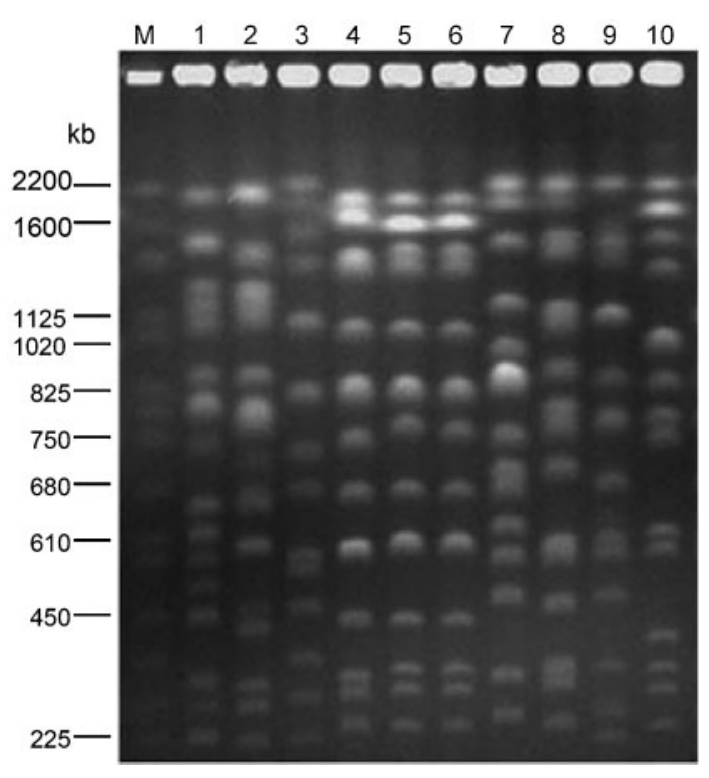

Fig. 2. Electrophoretic karyotypes. Lanes: M, Saccharomyces cerevisiae YNN 295; 1, S. bayanus AS $2.1885^{\top} ; 2$, S. pastorianus AS $2.2402^{\top} ; 3, S$. kudriavzevii AS $2.2408^{\top} ; 4,5$ and $6, S$. arboricolus sp. nov. $\mathrm{H}-6^{\top}, \mathrm{ZX}-15$ and ZX-20, respectively; $7, S$. mikatae AS $2.2407^{\top} ; 8$, S. paradoxus AS $2.2401^{\top}$; 9 , S. cerevisiae AS $2.1882^{\top} ; 10$, S. cariocanus AS $2.2374^{\top}$.

Saccharomyces sensu lato (Vaughan-Martini et al., 1993; Fischer et al., 2000; Naumov et al., 1992, 1995; Petersen et al., 1999; Lu et al., 2004; Wu \& Bai, 2005). The electrophoretic karyotypes of strains $\mathrm{H}-6^{\mathrm{T}}, \mathrm{ZX}-15$ and ZX20 bore a superficial resemblance to those of the accepted Saccharomyces species, being consistent with their placement in this genus based on rDNA sequence analysis (Fig. 1).

The Saccharomyces species can easily be crossed in any combination, though interspecific hybrids formed are sterile (Naumov et al., 2000). This has probably resulted in the common introgression of genetic material in these species (Fischer et al., 2000) and in the ambiguous sequence differences between some of the species. For example, the two mating types of S. kudriavzevii have remarkable $26 \mathrm{~S}$ rDNA D1/D2 domain, protein gene EF- $1 \alpha$ and mitochondrial COX II sequence divergences, while $S$. bayanus and $S$. pastorianus possess identical D1/D2 and ITS sequences (Fischer et al., 2000; Kurtzman \& Robnett, 2003). Nevertheless, the genetic isolation of the population represented by the three Chinese strains from other Saccharomyces species seems clear, for the new strains differed from all the accepted Saccharomyces species significantly in ITS sequences (supplementary data) and retained a specific electrophoretic karyotyping profile (Fig. 2).

\section{Phenotypic characterization}

Strains $\mathrm{H}-6^{\mathrm{T}}$, ZX-15 and ZX-20 exhibited similar morphological and physiological characters that are typical for the genus Saccharomyces. Each of them readily formed unconjugated asci containing two to four globose ascospores on YM (Yarrow medium) or acetate agar. The asci were persistent (Fig. 3). The strains vigorously fermented glucose, galactose, sucrose and raffinose. However, they can be differentiated from the type strains of the other species of the genus Saccharomyces by several key phenotypical characters (Naumov et al., 2000), as listed in Table 1.

The molecular and phenotypic comparison showed that strains $\mathrm{H}-6^{\mathrm{T}}, \mathrm{ZX}-15$ and $\mathrm{ZX}-20$ represent a novel species of the genus Saccharomyces, for which the name Saccharomyces arboricolus sp. nov. is proposed.

\section{Latin diagnosis of Saccharomyces arboricolus F.-Y. Bai \& S.-A. Wang sp. nov.}

In media liquido $\mathrm{YM}$ post dies 3 ad $25{ }^{\circ} \mathrm{C}$, cellulae ellipsoideae, $2.5-7.5 \times 2.5-10 \mu \mathrm{m}$, singulae, binae et adhaerentes. Per gemmationem multipolarem reproducentes. Post 1 mensem sedimentum formatur. In agaro farinae Zea maydis confecto pseudomycelium observatae. Ascosporae ovoideae, 2-4 in asco, ex ascis non liberantur.

Glucosum, galactosum, sucrosum et raffinosum fermentantur at non maltosum nec lactosum. Glucosum, galactosum, sucrosum, trehalosum (lente), melibiosum, raffinosum, melezitosum, D-mannitolum (varium) et $\alpha$-methyl-D-glucosidum assimilantur at non $\mathrm{L}$-sorbosum, maltosum (varium),
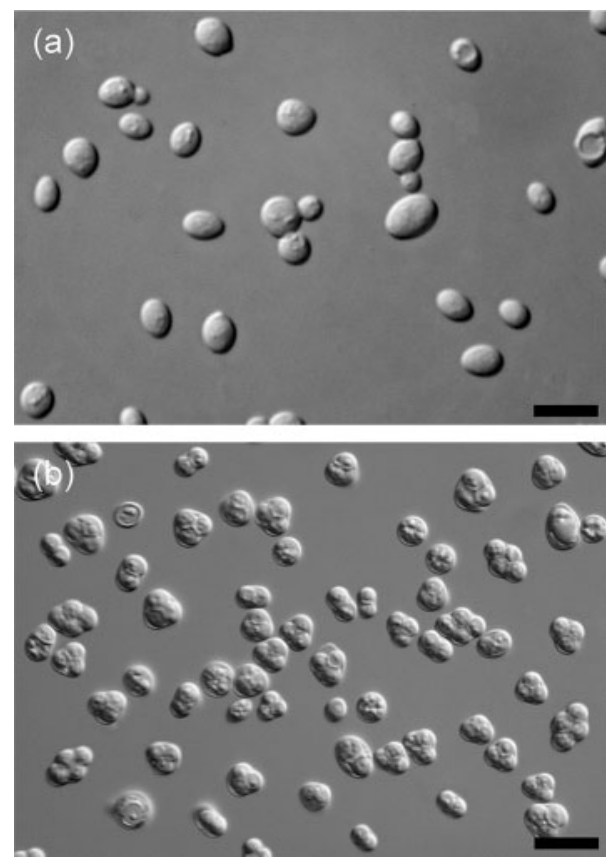

Fig. 3. Saccharomyces arboricolus sp. nov. $\mathrm{H}-6^{\top}$. (a) Vegetative cells grown in YM broth for 3 days at $25^{\circ} \mathrm{C}$. (b) Asci formed on acetate agar after 5 days at $25^{\circ} \mathrm{C}$. Bars, $10 \mu \mathrm{m}$. 
Table 1. Physiological characteristics that distinguish the type strains of Saccharomyces species

Strains: 1 , S. arboricolus sp. nov. AS $2.3317^{\mathrm{T}} ; 2$, S. bayanus CBS $380^{\mathrm{T}}$; 3, S. cerevisiae NCYC $505^{\mathrm{T}} ; 4$, S. paradoxus CBS $432^{\mathrm{T}} ; 5$, S. pastorianus NCYC $392^{\mathrm{T}}$; 6, S. cariocanus UFRJ $50816^{\mathrm{T}} ; 7$, S. kudriavzevii IFO $1802^{\mathrm{T}}$; 8, S. mikatae IFO $1815^{\mathrm{T}}$. + , Positive; - , negative; D, delayed positive; s, slow.

\begin{tabular}{|c|c|c|c|c|c|c|c|c|}
\hline Characteristic & 1 & 2 & 3 & 4 & 5 & 6 & 7 & 8 \\
\hline \multicolumn{9}{|l|}{ Fermentation of: } \\
\hline D-Galactose & + & - & - & - & - & + & - & + \\
\hline Maltose & - & - & - & - & - & - & S & - \\
\hline \multicolumn{9}{|l|}{ Assimilation of: } \\
\hline D-Galactose & + & + & + & + & + & + & - & + \\
\hline Maltose & - & + & + & + & + & - & - & + \\
\hline D-Mannitol & $\mathrm{D}$ & $\mathrm{D}$ & - & + & - & + & $\mathrm{D}$ & + \\
\hline Melibiose & + & - & - & - & - & - & - & $\mathrm{D}$ \\
\hline Trehalose & + & + & + & + & + & - & - & $\mathrm{D}$ \\
\hline Galactitol & - & - & - & + & - & - & + & + \\
\hline Inulin & - & - & $\mathrm{D}$ & - & - & - & + & - \\
\hline Methyl $\alpha$-D-glucoside & + & + & + & + & + & - & + & + \\
\hline
\end{tabular}

cellobiosum, lactosum, inulinum, amylum solubile, D-xylosum, L-arabinosum, D-arabinosum, D-ribosum, L-rhamnosum, D-glucosaminum, methanolum, ethanolum, glycerolum, erythritolum, ribitolum, galactitolum, salicinum, DL-lacticum, acidum succinicum, acidum citricum, inositolum nec hexdecanum. Ammonium sulfatum et ethylaminum assimilantur at non natrum nitrosum, kalium nitricum, L-lysinum net cadaverinum. Ad crescentiam vitamina externa necessaria sunt. Maxima temperatura crescentiae: $32{ }^{\circ} \mathrm{C}$. Materia amyloidea iodophila non formantur. Diazonium caeruleum B non respondens. Ureum non hydrolysatur.

\section{Description of Saccharomyces arboricolus F.-Y. Bai \& S.-A. Wang sp. nov.}

Saccharomyces arboricolus (ar.bo.ri'co.lus. N.L. masc. n. arboricolus, living in trees, referring to the source of the type strain).

In YM broth (Yarrow, 1998), after 3 days at $25{ }^{\circ} \mathrm{C}$, the cells are ellipsoid, $2.5-7.5 \times 2.5-10 \mu \mathrm{m}$ and occur singly, in pairs or in groups (Fig. 3a). Budding is multilateral. After 1 month at $25^{\circ} \mathrm{C}$, sediment is present. Pseudohyphae are observed in cultures grown on cornmeal agar. Oval asci containing two to four round ascospores are formed after incubation for 5 days at $25{ }^{\circ} \mathrm{C}$ on acetate or YM agar (Fig. 3b). Asci are persistent. Glucose, galactose, sucrose and raffinose are fermented; maltose and lactose are not fermented. Glucose, galactose, sucrose, trehalose (delayed), melibiose, raffinose, melezitose, D-mannitol (variable) and methyl $\alpha$-D-glucoside are assimilated; L-sorbose, maltose (variable), cellobiose, lactose, inulin, soluble starch, Dxylose, L-arabinose, D-arabinose, D-ribose, L-rhamnose, D-glucosamine, methanol, ethanol, glycerol, erythritol, ribitol, galactitol, salicin, DL-lactic acid, succinic acid, citric acid, inositol and hexadecane are not assimilated. Ammonium sulfate and ethylamine hydrochloride are assimilated; potassium nitrate, sodium nitrite, L-lysine and cadaverine hydrochloride are not assimilated. Growth in vitamin-free medium is positive. Maximum growth temperature is $32{ }^{\circ} \mathrm{C}$. Starch-like compounds are not produced. Diazonium blue B reaction is negative. Urease activity is negative.

The type strain, $\mathrm{H}-6^{\mathrm{T}}\left(=\mathrm{AS} 2.3317^{\mathrm{T}}=\mathrm{CBS} 10644^{\mathrm{T}}\right)$, was isolated from the bark of Quercus fabri Hance collected in Qinling Mountains, Shaanxi Province in west China in September 2006. This strain has been deposited in the China General Microbiological Culture Collection Center (CGMCC), Academia Sinica, Beijing, China, as AS $2.3317^{\mathrm{T}}$ $\left(=\right.$ CBS $\left.10644^{\mathrm{T}}\right)$.

\section{Acknowledgements}

We thank Professor J.-Y. Zhuang, Institute of Microbiology, Chinese Academy of Sciences, Beijing, China, for identifying the plant samples. This study was supported by grant no. 30470005 from the National Natural Science Foundation of China (NSFC).

\section{References}

Bai, F.-Y., Liang, H.-Y. \& Jia, J.-H. (2000). Taxonomic relationships among the taxa in the Candida guilliermondii complex, as revealed by comparative electrophoretic karyotyping. Int J Syst Evol Microbiol 50, 417-422.

Bai, F.-Y., Zhao, J.-H., Takashima, M., Jia, J. H., Boekhout, T. \& Nakase, T. (2002). Reclassification of the Sporobolomyces roseus and Sporidiobolus pararoseus complexes, with the description of Sporobolomyces phaffii sp. nov. Int J Syst Evol Microbiol 52, 2309-2314.

Fischer, G., James, S. A., Roberts, I. N., Oliver, S. G. \& Louis, E. J. (2000). Chromosomal evolution in Saccharomyces. Nature 405, 451-454.

Kurtzman, C. P. (2003). Phylogenetic circumscription of Saccharomyces, Kluyveromyces and other members of the Saccharomycetaceae, and the proposal of the new genera Lachancea, Nakaseomyces, Naumovia, Vanderwaltozyma and Zygotorulaspora. FEMS Yeast Res 4, 233-245.

Kurtzman, C. P. \& Robnett, C. J. (2003). Phylogenetic relationships among yeasts of the 'Saccharomyces complex' determined from multigene sequence analyses. FEMS Yeast Res 3, 417-432.

Lu, H. Z., Cai, Y., Wu, Z. W., Jia, J. H. \& Bai, F.-Y. (2004). Kazachstania aerobia sp. nov., an ascomycetous yeast species from aerobically deteriorating corn silage. Int J Syst Evol Microbiol 54, 2431-2435.

Makimura, K., Murayama, Y. S. \& Yamaguchi, H. (1994). Detection of a wide range of medically important fungi by the polymerase chain reaction. J Med Microbiol 40, 358-364.

Nakase, T. \& Suzuki, M. (1986). Bullera megalaspora, a new species of yeast forming large ballistospores isolated from dead leaves of Oryza sativa, Miscanthus sinensis, and Sasa sp. in Japan. J Gen Appl Microbiol 32, 225-240.

Naumov, G. I., Naumova, E. S., Lantto, R. A., Louis, E. J. \& Korhola, M. (1992). Genetic homology between Saccharomyces cerevisiae and its sibling species $S$. paradoxus and S. bayanus: electrophoretic karyotypes. Yeast 8, 599-612. 
Naumov, G. I., Naumova, E. S. \& Korhola, M. (1995). Karyotypic relationships among species of Saccharomyces sensu lato: S. castellii, S. dairensis, S. unisporus and S. servazzii. Syst Appl Microbiol 18, 103-108.

Naumov, G. I., James, S. A., Naumova, E. S., Louis, E. J. \& Roberts, I. N. (2000). Three new species in the Saccharomyces sensu stricto complex: Saccharomyces cariocanus, Saccharomyces kudriavzevii and Saccharomyces mikatae. Int J Syst Evol Microbiol 50, 1931-1942.

Petersen, R. F., Nilsson-Tillgren, T. \& Piskur, J. (1999). Karyotypes of Saccharomyces sensu lato species. Int J Syst Bacteriol 49, 1925-1931.

Rokas, A., Williams, B. L., King, N. \& Carroll, S. B. (2003). Genomescale approaches to resolving incongruence in molecular phylogenies. Nature 425, 798-804.
Sniegowski, P. D., Dombrowski, P. G. \& Fingerman, E. (2002). Saccharomyces cerevisiae and Saccharomyces paradoxus coexist in a natural woodland site in North America and display different levels of reproductive isolation from European conspecifics. FEMS Yeast Res 1, 299-306.

Vaughan-Martini, A., Martini, A. \& Cardinali, G. (1993). Electrophoretic karyotyping as a taxonomic tool in the genus Saccharomyces. Antonie Van Leeuwenhoek 63, 145-156.

Wu, Z.-W. \& Bai, F.-Y. (2005). Kazachstania aquatica sp. nov. and Kazachstania solicola sp. nov., novel ascomycetous yeast species. Int $J$ Syst Evol Microbiol 55, 2219-2224.

Yarrow, D. (1998). Methods for the isolation, maintenance and identification of yeasts. In The Yeasts, a Taxonomic Study, 4th edn, pp. 77-100. Edited by C. P. Kurtzman \& J. W. Fell. Amsterdam: Elsevier. 